Ferroel ectric properties of I ead- zi rconat e- ti t anate fi I ns prepared by I aser abl at i on

\begin{tabular}{|l|l|}
\hline 著者 & $\begin{array}{l}\text { Ki doh H deo, Ogawa Toshi o, Mbr i not o Aki har u, } \\
\text { Shi m zu Tat suo }\end{array}$ \\
\hline 著者別表示 & 森本 章治, 清水 立生 \\
\hline $\begin{array}{l}\text { j our nal or } \\
\text { publ i cat i on t i t l e }\end{array}$ & Appl i ed physi cs I ett er s \\
\hline vol une & 58 \\
\hline nunber & 25 \\
\hline page range & $2910-2912$ \\
\hline year & $1991-06-01$ \\
\hline URL & ht t p: //doi . or g/10. 24517/00007932 \\
\hline
\end{tabular}




\title{
Ferroelectric properties of lead-zirconate-titanate films prepared by laser ablation
}

\author{
Hideo Kidoh and Toshio Ogawa \\ Murata Manufacturing Co., Ltd., Nagaokakyo, Kyoto 617, Japan \\ Akiharu Morimoto and Tatsuo Shimizu \\ Department of Electronics, Faculty of Technology. Kanazawa University, Kanazawa 920. Japan
}

(Received 28 February 1991; accepted for publication 24 April 1991)

\begin{abstract}
Ferroelectric lead-zirconate-titanate (PZT) thin films have been deposited by excimer laser ablation on sapphire substrates with and without an electrode. In preparation for the films, $\mathrm{O}_{2}$ gas pressure has greatly influenced the film structure and morphology. For the first time, we have confirmed the ferroelectric properties of PZT films prepared by laser ablation without post-annealing. It appears to be possible to use these films for nonvolatile random access memories with some additional improvements in the film properties.
\end{abstract}

Ferroelectric ceramics such as $\mathrm{BaTiO}_{3}, \mathrm{PbTiO}_{3}$, and lead-zirconate-titanate (PZT) have many applications in piezoelectric and pyroelectric devices. PZT, in particular, has attracted great attention due to their high electromechanical coupling coefficients, $k$, and high relative dielectric constants, $\epsilon_{r}$ Recently, thin films of ferroelectric materials have become of great interest in device applications such as piezoelectric vibrators, ' surface acoustic wave (SAW) devices, ${ }^{2}$ pyroelectric detectors, ${ }^{3}$ and nonvolatile random access memories. ${ }^{4}$

For preparing these films, magnetron sputtering has conventionally been used. ${ }^{5,6}$ This method, however, has some disadvantages such as low deposition rate and large variations in composition. In order to overcome these disadvantages of the sputtering method, other methods such as sol-gel technique, ${ }^{7}$ metalorganic chemical vapor deposition $(\mathrm{MOCVD})^{8}$ and laser ablation ${ }^{9-14}$ are being used to prepare these thin films. In contrast with sol-gel technique and MOCVD which require special material sources, the laser ablation can use the ceramic target as a material source, which allows this method to be applied to a preparation of various kinds of thin films. In practice, the laser ablation method has been used for preparation of $\mathrm{Ba}_{2} \mathrm{YCu}_{3} \mathrm{O}_{x}$ superconducting films with excellent results.

The most promising characteristics of the laser ablation method are the following: (1) There is little difference in the composition between the target material and the deposited film. (2) Deposition in high oxygen pressures is possible because of the absence of energy sources such as filaments for the electron emission, heaters for the evaporation, or discharge electrodes in the system. (3) Since atoms ejected from the target have relatively high energy compared with that of thermal evaporation, it is possible to crystallize the films at relatively low substrate temperatures. (4) Even materials with a high melting point can be easily deposited if the materials strongly absorb the laser light.

In recent years, many groups, including ourselves, have reported the structural and compositional properties of ferroelectric thin films prepared by laser ablation. ${ }^{9-12}$ In addition, some groups reported the results of $D-E$ hysteresis measurements and confirmed the ferroelectricity of the post-annealed films. ${ }^{13.14}$ They, however, have not confirmed the ferroelectric properties of as-deposited films.

In this letter, we report the results of the structural and ferroelectric properties ( $D-E$ hysteresis) of as-deposited PZT films prepared by laser ablation using the ArF excimer laser.

A schematic view of the equipment for the preparation of PZT films is shown in Fig. 1. The film deposition was carried out by the ablation of a PZT ceramic target in a vacuum chamber with an $\mathrm{O}_{2}$ gas pressure of $27-267 \mathrm{~Pa}$ using an ArF excimer laser (SHIBUYA SQL2240, $193 \mathrm{~nm}$ wavelength, $10 \mathrm{~ns}$ pulse width, $5 \mathrm{~Hz}$ repetition rate). The ceramic target consists of a single-phase pellet of $\mathrm{Pb}\left(\mathrm{Zr}_{0.52} \mathrm{Ti}_{0.48}\right) \mathrm{O}_{3}$ with 1 wt. \% of $\mathrm{Nb}_{2} \mathrm{O}_{5}$. The substrates were an $r$-plane sapphire with an electrode to measure the ferroelectric properties and a $c$-plane sapphire. The substrate temperature, as measured by a thermocouple on the substrate surface, was controlled between 420 and $560^{\circ} \mathrm{C}$. The laser energy for the ablation was $70 \mathrm{~mJ} / \mathrm{shot}$, which corresponds roughly to a laser fluence of $3.5 \mathrm{~J} / \mathrm{cm}^{2}$ shot. After the ablation, the films were cooled to room temperature in $3 \mathrm{~h}$. X-ray diffraction (XRD) was carried out using $\mathrm{Cu} K \alpha$ at room temperature to investigate the film

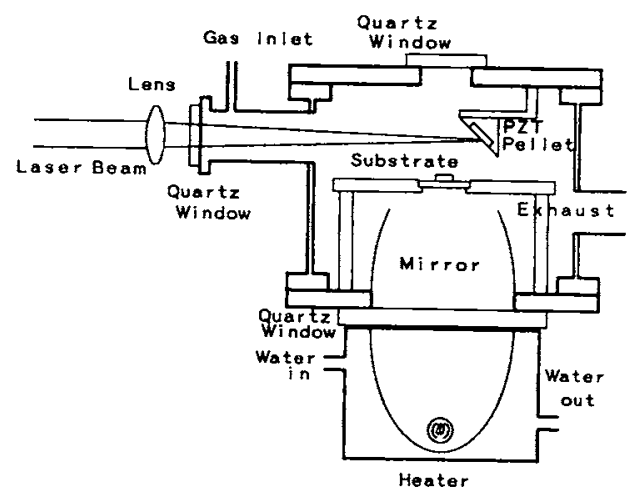

FIG. 1. Schematic view of the equipment for preparing PZT film using excimer laser ablation.

Reprinted frow Appl. Phys. Lett., Vol.58, No.25, pp.2910 2912 (1991) 


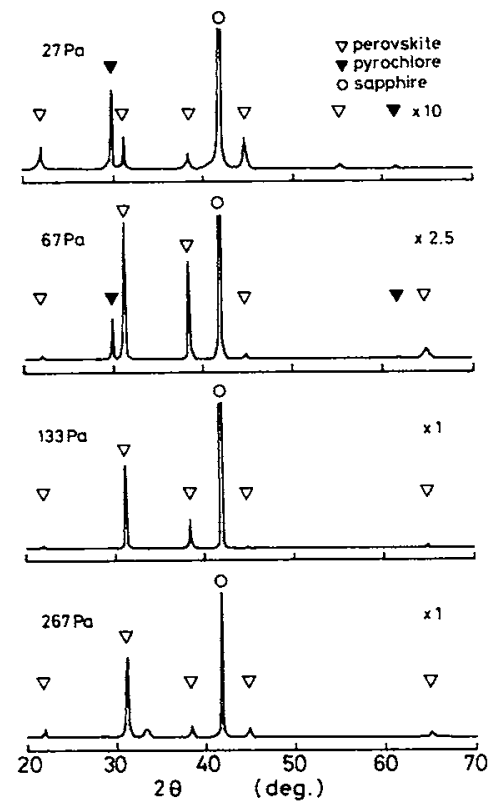

FIG. 2. XRD spectra for at a substrate temperature of $520^{\circ} \mathrm{C}$ under various $\mathrm{O}_{2}$ gas pressures.

structure. The morphology of the films was investigated by scanning electron microscopy (SEM). The $\epsilon_{r}$ and the dielectric loss factor, $\tan \delta$, were measured at $1 \mathrm{kHz}$ using an LCR meter. $D-E$ hysteresis loop was observed using a Sawyer-Tower circuit at $60 \mathrm{~Hz}$.

The XRD spectra of the PZT films on sapphire $c$ plane prepared at a substrate temperature of $520^{\circ} \mathrm{C}$ under various $\mathrm{O}_{2}$ gas pressures are shown in Fig. 2. Open and closed triangles indicate the peaks for the perovskite and pyrochlore phase of PZT, respectively. Open circles indicate the peaks due to the sapphire substrate. As shown in Fig. 2, both the peaks for perovskite phase and pyrochlore phase are observed at a gas pressure of $27 \mathrm{~Pa}$. Increasing gas pressure, however, the perovskite phase becomes dominant. At the gas pressure of $133 \mathrm{~Pa}$, the pyrochlore phase disappears, resulting in the perovskite single phase. The peak intensity of (110) and (111) planes of the perovskite phase is stronger than that from the other planes in comparison with those of the polycrystalline bulk target. When the gas pressure reaches $267 \mathrm{~Pa}$, however, the peak of an unknown phase appears around $2 \theta=33.5^{\circ}$ besides the peaks for the perovskite phase. On the other hand, at a substrate temperature of $470^{\circ} \mathrm{C}$, most peaks are from the pyrochlore phase at the gas pressure of $27 \mathrm{~Pa}$. When the pressure reaches $133 \mathrm{~Pa}$, in a similar case as shown in Fig. 2 , all the peaks are completely converted to those for the perovskite phase. As for the dependence of the deposition rate on $\mathrm{O}_{2}$ gas pressure, up to the pressure of $133 \mathrm{~Pa}$, the deposition rate decreases gradually with increasing the gas

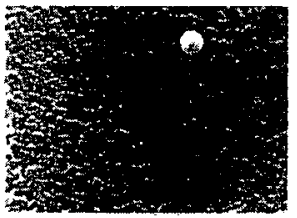

(a)

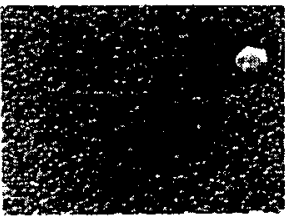

(c)

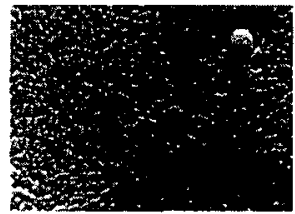

(b)

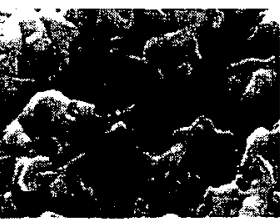

(d)
FIG. 3. SEM photographs of the deposited films prepared under various $\mathrm{O}_{2}$ gas pressures of (a) $27 \mathrm{~Pa}$, (b) $67 \mathrm{~Pa}$, (c) $133 \mathrm{~Pa}$, and (d) $267 \mathrm{~Pa}$ at a substrate temperature of $520^{\circ} \mathrm{C}$.

pressure. It suddenly decreases, however, at a pressure of $267 \mathrm{~Pa}$.

SEM photographs of the deposited films prepared at a substrate temperature of $520^{\circ} \mathrm{C}$ under various $\mathrm{O}_{2}$ gas pressures are shown in Fig. 3. Increasing the gas pressure up to $133 \mathrm{~Pa}$, the size and the shape of grains become slightly smaller and spherical, respectively. At a pressure of 267 $\mathrm{Pa}$, however, the lumps on the order of microns appear and the morphology of the film surface suddenly becomes rough. From the $x$-ray diffraction spectra, the film morphology, and the deposition rate, it can be seen that $\mathrm{O}_{2}$ gas pressure of $133 \mathrm{~Pa}$ is suitable for preparing PZT films.

To investigate the ferroelectric properties of PZT films, we used the film electrode on an r-plane sapphire as a substrate. After the deposition of PZT film by laser ablation, the film electrode was deposited as upper electrode at room temperature. The crossed area between the upper and lower electrodes was $1 \mathrm{~mm}^{2}$. Figure 4 shows the $D-E$ hysteresis loop of the as-deposited PZT film prepared at an $\mathrm{O}_{2}$ gas pressure of $133 \mathrm{~Pa}$ on a substrate temperature of $520^{\circ} \mathrm{C}$. The observed loop is asymmetric, which suggests

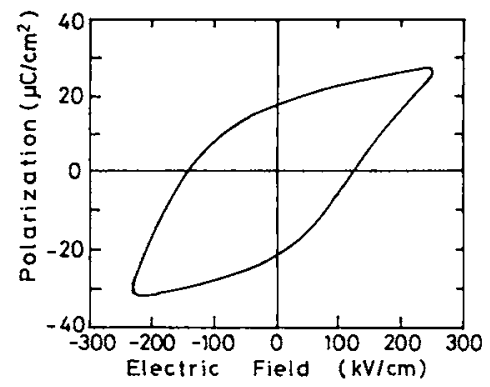

FIG. 4. $D-E$ hysteresis loop for a 1.3- $\mu$ m-thick PZT film prepared by laser ablation. 
TABLE I. Ferroelectric properties of the PZT films.

\begin{tabular}{lcccccc}
\hline \hline $\begin{array}{l}\tau_{s} \\
\left(\mathrm{C}^{\circ}\right)\end{array}$ & $\begin{array}{c}\text { Pressure } \\
(\mathrm{Pa})\end{array}$ & $\begin{array}{c}\text { Thickness } \\
(\mu \mathrm{m})\end{array}$ & $\epsilon_{r}$ & $\begin{array}{c}\tan \delta \\
(\%)\end{array}$ & $\begin{array}{c}P_{r} \\
\left(\mu \mathrm{C} / \mathrm{cm}^{2}\right)\end{array}$ & $\begin{array}{c}E_{c} \\
(\mathrm{kV} / \mathrm{cm})\end{array}$ \\
\hline 520 & 27 & 0.50 & 84 & 6.3 & $\ldots$ & $\cdots$ \\
560 & 27 & 1.0 & 207 & 19.1 & 5 & 115 \\
520 & 133 & 1.3 & 350 & 4.8 & -20 & 130 \\
\hline \hline
\end{tabular}

that the films are already polarized in the as-deposited state. The average values of the remanent polarization $P_{r}$ and the coercive field $E_{c}$ are $20 \mu \mathrm{C} / \mathrm{cm}^{2}$ and $130 \mathrm{kV} / \mathrm{cm}$, respectively. The value of $P_{r}$ is larger than the reported values of the films prepared by laser ablation with post-annealing ${ }^{13,14}$ and is almost the same as those of the films prepared by other methods such as conventional rfmagnetron sputtering. ${ }^{2,5}$ On the other hand, the value of $E_{c}$ is larger than the reported values. ${ }^{2}$ It is considered that this is due to the small grain size of our film. The relative dielectric constant $\epsilon_{r}$ of this film is 350 which is much smaller than that of the bulk target of 1900 . The results of ferroelectric properties of PZT films and the preparation conditions are summarized in Table $I$.

In summary, we have shown that PZT thin films with single perovskite phase can be grown on sapphire substrate using excimer laser ablation and relatively high oxygen pressure is suitable for preparing the perovskite phase. In addition, we directly confirmed the ferroelectric properties of the PZT films without post-annealing by measuring $D-E$ hysteresis loop. Considering the values of $P_{r}$ and $E_{c}$, the laser ablation is suitable for preparing PZT films. Additional improvements in the film properties, such as crystal orientation, would make it possible to use these films in nonvolatile random access memories.

We would like to thank Professor M. Kumeda of Kanazawa University for his helpful discussions. We would also like to thank T. Minamikawa and Y. Yonezawa of the Industrial Research Institute of Ishikawa Prefecture for their help and useful discussions in our experiments. We would also like to thank $H$. Yashima for his help in our experiments. We are grateful to Shibuya Kogyo Co., Ltd. for supplying the ArF excimer laser system. The authors (A.M. and T.S.) wish to thank the Murata Science Foundation for supporting this work in part. The authors $(\mathrm{H}$. K. and T. O.) wish to thank the Research Development Corporation of Japan for supporting this work in part.

${ }^{1}$ K. Kushida and H. Takeuchi, Appl. Phys. Lett. 50, 1800 (1987)

${ }^{2}$ K. Sreenivas and M. Sayer, J. Appl. Phys. 64, 1484 (1988).

${ }^{3}$ K. Iijima, Y. Tomita, R. Takayama, and I. Ueda, J. Appl. Phys. 60, 361 (1986).

J. F. Scott, J. Appl. Phys. 64, 787 (1988).

${ }^{5}$ R. Takayama and Y. Tomita, J. Appl. Phys. 65, 1666 (1989).

${ }^{6} \mathrm{~S}$. Ibuki, T. Nakagawa, M. Okuyama, and Y. Hamakawa, Jpn. J. Appl Phys. 29, 532 (1990).

${ }^{7}$ L. E. Sanches, S. Y. Wu, and I. K. Naik, Appl. Phys. Lett. 56, 2399 (1990).

${ }^{8}$ M. Okada, K. Tominaga, T. Araki, S. Katayama, and Y. Sakashita, Jpn. J. Appl. Phys. 29, 718 (1990).

${ }^{9}$ S. Otsubo, T. Maeda, T. Minamikawa, Y. Yonezawa, A. Morimoto, and T. Shimizu, Jpn. J. Appl. Phys. 29, L133 (1989).

${ }^{10}$ G. M. Davis and M. C. Gower, Appl. Phys. Lett. 55, 112 (1989).

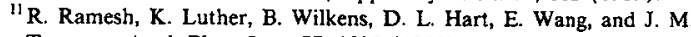
Tarascon, Appl. Phys. Lett. 57, 1505 (1990).

${ }^{12}$ A. Morimoto, S. Otsubo, T. Shimizu, T. Minamikawa, Y. Yonezawa, H. Kidoh, and T. Ogawa, Mat. Res. Soc. Symp. Proc. 191, 31 (1990).

${ }^{13}$ K. L. Saenger, R. A. Roy, K. F. Etzold, and J. J. Cuomo, Mat. Res. Soc. Symp. Proc. 200, 115 (1990),

${ }^{14}$ C. K. Chiang, L. P. Cook, P. K. Schenck, P. S. Brody, and J. M. Benedetto, Mat. Res. Soc. Symp. Proc. 200, 133 (1990). 